\title{
Information Needs, Search Behaviors, and Use of Elementary School Teachers on the Internet
}

\author{
Chiung-Wen Chien, M.L.S. \\ Shan-Ju L. Chang, Ph.D. \\ Department of Library and Information Science \\ National Taiwan University
}

\begin{abstract}
This paper discusses Internet-related information behaviours of elementary school teachers in Taiwan, investigating their information needs, seeking behaviors, and use within an educational context. This study places an emphasis on investigating both work and non-work related use of Internet information by elementary school teachers. Research participants responded to a questionnaire on their internet search behaviours. In-depth interviews of 30 respondents were then performed. Results show that the boundary between work and non-work related use of the Internet is blurring. Participating elementary school teachers in Taiwan use the Internet for many tasks, and there are several technical and personal barriers to overcome before the technology can be fully utilized in the daily activities of educators.
\end{abstract}

\section{Introduction}

Information is an essential part of life. As history progresses, people need more and more information to face their complicated and changeable work and living environments. With the rise of the Internet, the information environment has become much more complicated; searching for and using Internet information is one of today's newest challenges.

Describing, analysing and organizing human information behaviors are the three foundations of information services. The academic field of Information Behavior Studies seeks to assist information services with diagnosing people's information needs, increasing the efficiency of information design, and mediating between with the information services, of human information behaviors, and restriction and information systems (Chang, 2001).

Elementary school teachers in Taiwan comprise a group whose work is dependent on, and will continue to be dependent on information as they carry on teaching throughout their careers. The Ministry of Education of Taiwan has spared no effort to encourage information education. In recent years, more and more elementary school teachers have begun to use Internet information to assist in their teaching. Due to such encouragement, elementary school teachers have gradually formed numerous large communities on the Internet. This study attempts to understand information needs, seeking behaviours, and use within an educational context, with an emphasis on investigating both work and non-work related use of the Internet by elementary school teachers in Taiwan. The main goals of this research are as follows:

1. To investigate both work and non-work related use of the Internet by elementary school teachers, and to systematically describe the Internet information behaviors of elementary school teachers. 
2. To compare elementary school teachers work related Internet information behaviors with non-work related Internet information behaviors.

3. To understand elementary school teachers' views on Internet resources, and propose suggestions to information services on improving such resources.

\section{Literature Review}

Savolainen (1999) used interviews to explore the features of work and non-work information seeking in Tampere, Finland. Whether taking place within a work or a non-work information seeking context, the World Wide Web, e-mail and discussion groups appeared to be the most frequently used information resources. Interviewees expressed several main factors of using the internet: (1) It is easy to access a huge amount of data; (2) It is easy to save time; (3) It is easy to save money; (4) It provides the chance to consult a number of experts with a single request; (5) It allows for independence in the specific time and place of information seeking. Comparing with traditional media, difficulties faced while using electronic sources include: (1) Requiring a specific interface; (2) A willingness to learn computer skills; (3) Ensuring networked sources are up-to-date and reliable; (4) Slow response times; (5) Temporary breakdowns during data transmission; (6) The fragmented, sometimes even chaotic nature of the internet; and (7) The inconvenience of reading large amounts of text on computer screens.

Hack and Sue (1997) found that the use of internet resources by teachers is proportionally lower than use by students, and that surfing the Internet tends to take place at home. Liu (1998) found that 35.8\% of the elementary school teachers of Pingtung County, Taiwan use the Internet, also tending to surf at home. Liu states that the main reasons the teachers use the Internet include: accessibility of the Internet at any time and the abundant resources available. Teachers used the Internet to look for materials relevant to teaching, recreation and amusement, for E-mailing, etc.

According to Huang (2000), 95.9\% of Taipei's elementary school teachers have used the internet, and already understand the functions and basic applications of internet resources. Most often used Internet resources include the World Wide Web and e-mail; while Internet resource that are seldom used include IRC and NetNews. The availability and usage of Internet related equipment, education experience, and experience with Internet information influence how teachers use the Internet.

Liu's study was limited to the elementary school teachers of Pingtung County, and Huang's study was limited to the teachers of Taipei city. But CommonWealth Magazine (2000) has conducted a nationwide investigation of the abilities and use of the information network by teachers. They find that usage of the internet by teachers in middle and elementary schools is broken down as follows: surfing the Internet and searching for teaching materials - 36.5\%; utilizing computers or the internet to set exam papers - $62 \%$; updating curriculum and preparing for teaching - 57.5\%; calculating grades - 53.9\%; and assigning homework $-43.1 \%$. Only $19.9 \%$ of the teachers use computers or the internet during actual teaching in the classroom. 
Reviewing the past studies about teacher's information behaviors, relevant themes discussed rely mainly on library affairs, such as use of the library, the types of library materials used, the ways in which library resource are searched, and the satisfaction with what the library serves and proposes, etc. After the rise of the Internet, many researchers have studied on-line database and Internet use. But there is still a lack in the study of elementary school teachers' information behaviors. Questions that need to be addressed include: What situations produce the information needs of elementary school teachers? How do teachers search the Internet for information? How do Teachers utilise Internet information?

\section{Research Design and Methods}

This study investigated Internet use experiences of elementary school teachers using a questionnaire survey followed by in-depth interviews of selected participants.

\section{Questionnaire}

This study bases on information behavior and Internet use literature to develop a questionnaire, collect elementary school teachers' basic answers on Internet information use, and choose experienced users for in-depth interview following the questionnaire.

The questionnaire is divided into two major parts. The first part, focussing on experiences using the Internet, amounts to 20 questions on the following topics:

- frequency and amount of time of Internet use

- location of Internet use

- main purpose of Internet use

- Internet tools and resources that are often used

- Most impressive Internet resources

- how new Internet resources are discovered

- difficulties encountered throughout the course of Internet use

- frequency of work related Internet use

- application of work related Internet use

- importance of work related Internet use

- frequency of non-work related Internet use

- application of non-work related Internet use

- importance of non-work related Internet use

The second part surveys demographic information, including sex, age, seniority of teaching, location of teaching, teaching subject, other positions held, time of Internet use, participation in Internet courses, and Internet accessible computer equipment availability. In addition, included is a question calling for volunteer interviewees at the end of the questionnaire. Data from the questionnaire were analysed according to the standard procedures of statistical analysis software SPSS, to understand the Internet use experience of the elementary school teachers.

Participants were chosen using two methods. In the first method, 1500 E-mail addresses were randomly chosen by searching for primary school elementary school teachers using the register of national primary schools on the websites of the Ministry of Education. These teachers were invited to voluntarily fill out and answer the questionnaire. The second 
method was to ask the Taiwan School Net to help distribute the questionnaire to affiliated members of the E-mail. Taiwan School Net, which was established in July, 2000, as a noncommercial educational professional website. Questionnaires were distributed and collected form October 6 to October 25, 2002.

258 questionnaires were collected, with 245 questionnaires being complete and useable. Of the completed questionnaires, male and female respondents each accounted for half of the total, with most respondents in the 30-39 year age range. Most participants were located in Taipei county and city. Most participants had 5 years of teaching experience on average. Close to $90 \%$ of participants have used Internet resources for at least three years. Nearly $80 \%$ have participated in Internet curriculum correlation activities. More than 90\% have access to the Internet at home, while more than $80 \%$ use the Internet every day. Most respondents used of the Internet for 2-5 hours every week, and most internet use took place on the school campus or at home.

\section{Interview}

After the initial analysis of responses to the questionnaire, 30 elementary school teachers were chosen for further in depth interviews. Only questionnaire respondents with more than three years of experience in using information sources on the Internet were chosen. Of this group, interviewees of both sexes and varying ages were chosen.

During interviews participants were asked questions on a number of topics, including: needs for information on the Internet, information search activities on the Internet, the use of information found on the Internet, advantages and problems associated with searching for and using Internet information, suggestions for Internet information services and the ideal Internet information that can be useful in teaching. Interview

Of the 30 interviewees, 14 were women (47\%), and 16 men (53\%). 15 interviewees were in the 30-39 year old age range. 14 interviewees are homeroom teachers, with the other 16 teaching in specific subjects. 15 of the teachers interviewed hold concurrent positions. Interviewees teach in both local and city schools, with most interviewees, 9 in all (30\%), teaching in Taipei. On average, interviewees had 7.7 years of teaching experience, with 7.2 years of experience searching for information on the Internet.

\section{Questionnaire Analysis}

Results of the questionnaire are summed up as follows:

\section{Purpose of Internet use:}

The main purposes of elementary school teacher Internet use were to receive and send E-mails, and to search for information to be used in teaching. Several obvious differences in the purposes of Internet were correlated to respondents sex, amount of time spent using the Internet, and whether or not the respondent had taken courses on using the Internet. 


\section{Internet use behaviors:}

(1) The Internet tools that respondents most often used were E-mail ,the World Wide Web and FTP.

(2) Internet resources that respondents most often used were Websites, Search Engines and Electronic Newspapers.

(3) Types of Internet information most often viewed were teaching materials relevant to the teacher's subject, training and research materials, and news.

(4) Specific Internet channels and websites most often used were Search engines, hyperlinks on the Web, and E-mail.

(5) Difficulties respondents most often faced while using Internet resources were a lack of time to filter information, low transmission speeds, and not being able to find the materials needed.

\section{Ways in which Internet information is used:}

(1) Respondents most often used information found on the Internet to prepare course content, prepare teaching materials, and keep up-to-date with new content. The Internet was most often used to search for necessary materials, enrich teaching content, and promote teacher's ability to do things on their own.

(2) Outside of work-related Internet use, respondents most often used the Internet to search for general information related to their lives, make reservations / book tickets, and simply browse for non-work related information. Non-work related Internet use was focussed on searching for needed materials, enriching their lives through general learning of subjects of interest, and searching for information to help solve problems relevant to the respondents personal lives.

\section{Evaluation of Internet information:}

(1) Respondents most often stated that the advantages of using the Internet include the abundant and completeness of Internet information sources, the convenience of searching for information, and the relative quickness of finding information on the Internet.

(2) Respondents most often stated that disadvantages of using the Internet include slow transmission and data retrieval speeds, information content being out of date, and information content being incomplete.

\section{Interview Analysis}

Analysis of interviewees' information needs, information search behaviours, and information use were carried out in both work and non-work related contexts. The analysis proposes a number of similarities and differences between elementary school teachers and other research groups. The following sections sum up the result of in-depth interview, and propose a model of the elementary school teachers' Internet information behavior.

\section{Comparison of work with non-work Internet information behaviors}


The similarities and differences of the Internet information behaviours in terms of information needs, information search behaviors, and information use are shown in table 1.

Table 1 : The Elementary school teachers' work and non-work Internet information behavior

\begin{tabular}{|c|c|c|}
\hline & Work & Non-Work \\
\hline $\begin{array}{l}\text { Information } \\
\text { need }\end{array}$ & $\begin{array}{l}\text { 1.Disseminate knowledge } \\
\text { 2.Find new information for Teaching } \\
\text { 3.Develop courses } \\
\text { 4.Obtain new specialized knowledge } \\
\text { 5.Demonstrate teaching methods } \\
\text { 6.Confirm teaching material validity }\end{array}$ & $\begin{array}{l}\text { 1. } \quad \text { Leisure and recreation. } \\
\text { 2. Acquire News. } \\
\text { 3. } \\
\text { Exchange personal information. }\end{array}$ \\
\hline \multirow[t]{3}{*}{$\begin{array}{l}\text { Information } \\
\text { search } \\
\text { behaviors }\end{array}$} & $\begin{array}{l}\text { Most often used internet resource: } \\
\text { 1.Search Engines } \\
\text { 2.Websites: } \\
\text { (1) Teaching Information } \\
\text { Websites. } \\
\text { (2) Teaching institution } \\
\text { Websites. } \\
\text { (3) Professional Teachers' Group } \\
\text { websites. }\end{array}$ & $\begin{array}{l}\text { Most often used internet resources: } \\
\text { 1.Search Engines } \\
\text { 2. Portal Sites } \\
\text { 3.E-Papers }\end{array}$ \\
\hline & $\begin{array}{l}\text { Information sites: } \\
\text { 1. Search Engines } \\
\text { 2. Recommend sites } \\
\text { 3. Interpersonal Relationship sites } \\
\text { 4. Research and Study sites } \\
\end{array}$ & $\begin{array}{l}\text { Information sites: } \\
\text { 1. Search Engines } \\
\text { 2. My Favorites } \\
\text { 3. E-Papers } \\
\text { 4. Interpersonal Relationship sites }\end{array}$ \\
\hline & $\begin{array}{l}\text { Search methods: } \\
\text { 1.Search terms are simple and short } \\
\text { 2.Search Strategies include: } \\
\text { (1) Brief Searches } \\
\text { (2) Block Building searches } \\
\text { (3) Citation Pearl Growing searches } \\
\text { 3.Short Search Times }\end{array}$ & \\
\hline $\begin{array}{l}\text { Information } \\
\text { use }\end{array}$ & $\begin{array}{l}\text { 1.Serve as teaching aids } \\
\text { 2.Help the teacher to understand } \\
\quad \text { course content } \\
\text { 3.Increase efficiency of student } \\
\text { learning } \\
\text { 4.Discover different types of teaching } \\
\text { information } \\
\text { 5.Inspiration of new teaching ideas } \\
\text { 6.Increase student motivation } \\
\text { 7.Validate specific information } \\
\text { 8.Solve other problems in the teaching } \\
\text { environment }\end{array}$ & $\begin{array}{l}\text { 1.Advice and assistance for life } \\
\text { 2.Leisure and recreation } \\
\text { 3. Strengthen interpersonal } \\
\quad \text { relationships } \\
\text { 4.Keep abreast of news } \\
\text { 5.Obtain information tools } \\
\text { 6.Solve non-work related problems }\end{array}$ \\
\hline
\end{tabular}


Based on the interview data, six characteristics of the Internet information behavior of elementary school teachers were identified: 1 . Internet information behaviors are directed by tasks at work and situations in daily life. 2. Interpersonal networks are used as important sources of information. 3. Both mainstream information and leisure information are equally important. 4. Appropriateness and correctness are two criteria used in assessing information. 5. Most Internet information needs to be transformed into teaching materials to be useful in the classroom. 6. The boundary of work related information seeking and non-work related information seeking is not clearly defined.

\section{A model of elementary school teachers' Internet information behavior.}

These results suggest a model of elementary school teachers' Internet information behaviour, to be used as reference for relevant research.

The central theory of this model is derived from interview results of this study. As Fig. 1 shows, elementary school teachers' Internet information behaviors are caused mainly by tasks and life situations, producing Information relevant to work and non-work issues. Workrelated Internet information needs are mainly centered on teaching needs, including spreading knowledge, supplementing teaching information, extending the teaching material of specific courses, obtaining new specialized knowledge, demonstrating teaching methods, and confirming the validity of information in teaching material. Non-work Internet information needs focussed on leisure and recreation, obtaining new knowledge, and exchanging personal information.

Elementary school teachers' main information sources included Search engines and Interpersonal relationship sites for both work and non-work related needs.

In terms of Internet information use, elementary school teachers use information in many ways according to the different problems and situations that arise. This is due to the fact that the work related Internet information needs of elementary school teachers lies mainly in teaching-related issues. Therefore Internet information is most often used in teaching activities including serving as teaching aids, helping the teacher to understand course content, increasing the results of student's learning, and so on. It appears that there are various ways to use non-work related information, such as providing assistance in life, offering recreational amusement, strengthening interpersonal relationships.

Using Internet information can influence the elementary school teachers' work and non-work life, as the Internet becomes the main information channel for both work and nonwork information needs. 


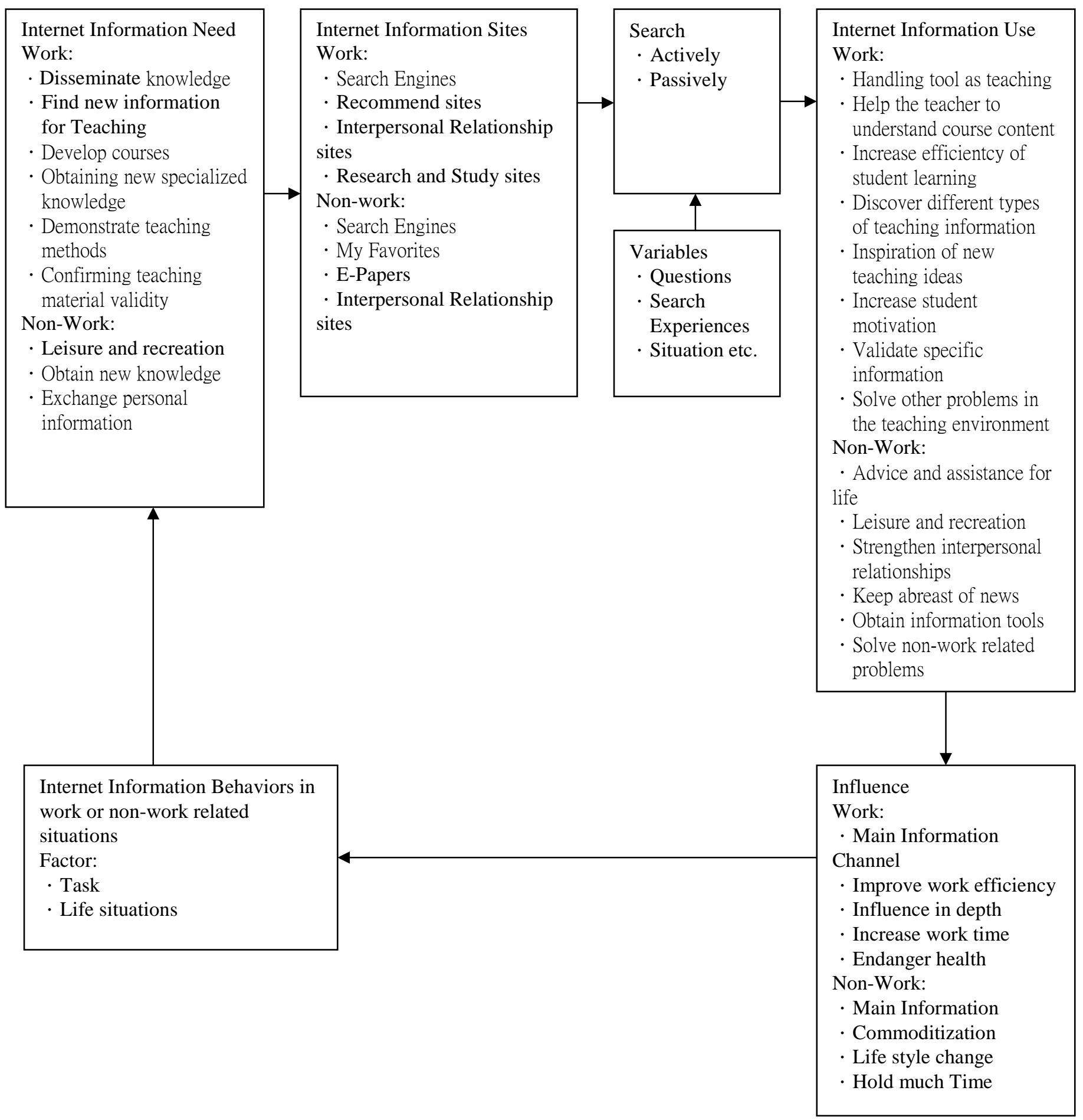

Fig 1: Model of Elementary School Teachers' Internet Information Behaviors 


\section{Conclusion}

This study finds that: 1. Elementary school teachers' information behaviors on the Internet are mainly influenced by situational factors; 2 . The needs for Internet information of elementary school teachers are mainly related to teaching; 3. Elementary school teachers are not only Internet information users, but also Internet information providers; 4. Information literacy is the key for elementary school teachers to incorporate Internet information into teaching; 5. Internet resources for elementary school education in Taiwan need to be integrated; 6.Eelementary school teachers are not familiar with services offered in school libraries in Taiwan.

This study shows that no matter whether in a work or non-work context, the Internet has become elementary school teachers' main information channel, and the boundary line between work and non-work information behaviors is quite fuzzy. Librarian and Information Services personnel should serve as information navigators, offering elementary school teachers appropriate Internet information services. Being completely familiar with education Internet resources, and fully grasping teachers' information needs will enable information services to help teachers obtain appropriate information.

\section{References}

Chang, S.-J. (2001). Information Behavior. In Lai, Ting-Ming, Library and Information Science. Taipei County : National OPEN University.

CommonWealth Magazine (2000). 教師運用資訊網路能力調查. 天下亲誌 2000 年教育特刊: 海闊天空 $I V$ 網上學習: Taipei City：CommonWealth Magazine.

Davis, R. W. (1987). A study of information needs, behaviors, and required information services of Oregon educators. Unpublished doctoral dissertation, University of Oregon.

Hack, L., \& Sue, S. (1997). A Survey of Internet Use by Teachers in Three Urban Connecticut Schools. School Library Media Quarterly, 25(3),151-155.

Huang, Y.-C. (2000). 臺北市立國民小學教師資訊素養知能及其相關設備利用情形之研究. Unpublished doctoral dissertation, National Taiwan Normal University,Taipei.

Liu, K.-L. (1998). An Investigation of Information Needs and Information Seeking Behavior of Elementary School Teachers in Pingtung Area. Unpublished doctoral dissertation, Fu Jen Catholic University.

Savolainen, R. (1999). The role of the internet in information seeking. Putting the networked services in context. Information Processing and Management, 35(6), 765-782.

Turner, P. M. (1996). What Help do Teachers Want, and What Will They do Get it? School Library Media Quarterly, 24(4), 208-212. 